\title{
Гносеология развития категории «экономические интересы»
}

\author{
И. С. Миронова ${ }^{1 凶}$, С. М. Сотников ${ }^{2}$ \\ 1,2 Воронежский государственный университет, Университетская пл., 1,394018, Воронеж,Российская Федерация
}

Для цитирования: Миронова И. С., Сотников С. М. Сравнительная характеристика содержательных элементов экономического анализа и бизнес-анализа // Вестник Воронежского государственного университета. Серия: Экономика и управление. 2021. № 1. С. 25-36. DOI: 10.17308/econ.2021.1/3347

\begin{abstract}
Предмет. Экономические отношения между агентами рыночной системы по поводу возникновения и существования экономических интересов, а также анализ теоретических и методологических проблем сущности и содержания категории «экономические интересы» как важнейшего мотива и стимула деятельности субъектов в концепциях зарубежных и отечественных исследователей этой проблемы.

Цель. Предпринята попытка уточнить содержание экономической категории «экономические интересы»; выявить взаимозависимости и взаимообусловленности экономических интересов и потребностей; определить, что из них первично, а что - вторично; исследовать это понятие как сложную иерархически соподчиненную систему.

Методология. В процессе изучения проблем возникновения и развития экономических интересов хозяйствующих субъектов использовались методы системно-функционального анализа, научной абстракции, общего и особенного, анализа и синтеза, восхождения от конкретного к абстрактному и наоборот, единства исторического и логического подходов.

Результаты. Осуществлен анализ основных положений, отражающих содержание рассматриваемой категории, выявлена её взаимосвязь с потреблением, отражена специфика этих отношений, указаны формы проявления интересов в реальной действительности. Авторами дано содержание категории «экономический интерес», которая представляет собой иерархическую систему, включающую следующие аспекты: первый - объективность, так как эти отношения возникают независимо от воли и сознания людей; второй - реализация экономического интереса способствует удовлетворению потребностей индивидов; третий - объективно-субъективный характер проявления в реальных условиях, потому что экономический интерес по своей природе объективен, но реализуется посредством субъективной деятельности людей.

Выводы: уточнено содержание категории «экономический интерес» как необходимости удовлетворения в первую очередь материальных потребностей хозяйствующих субъектов посредством социально-экономических отношений. Экономический интерес представляет собой многоуровневую сложноподчиненную иерархическую систему, которой присуща объективность, направленность на удовлетворение потребностей индивидов, объективно-субъективная форма проявления в реальной действительности.
\end{abstract}

Ключевые слова: экономические интересы, противоречия, модели, хозяйствующие субъекты, удовлетворение потребностей, производственные отношения, экономические отношения, экономическая выгода, мотивы деятельности, отношения собственности, экономическая категория, объективность, общественное воспроизводство, стимулы трудовой деятельности.

\section{Введение}

Функционирование современной российской экономической системы базируется на использовании различных типов и форм собственности, а также на основе возникновения принципиально иных постсоветских производственных и социально-экономических отношений, результатом проявления которых в действительности выступают экономиче- ские интересы. Новое содержание производственных (социально-экономических) отношений и перераспределение собственности между отдельными хозяйствующими субъектами привели к значительному расслоению агентов рыночной экономики. При этом экономические интересы банковских и предпринимательских структур, членов акционерных обществ возросли в кратном размере, а инте-

(C) Миронова И. С., Сотников С. М., 2021

Вестник ВГУ. Серия: Экономика и управление. 2021. № 1. С. 25-36. 
ресы государства и наемных работников приобрели тенденцию к резкому понижению.

В настоящее время теория экономических интересов, сформулированная советскими учеными на основе марксистской парадигмы о приоритете общих экономических интересов по сравнению с личными и коллективными, утратила свою актуальность. Более того, в этих рамках экономический интерес и экономическая потребность отождествлялись.

Современная концепция экономических интересов и возникающих при этом противоречий еще в должной мере не сформирована. Кроме того, необходимо отметить значительное сокращение предпочтений исследователей к изучению указанных проблем. Как следствие подобной ситуации, требуется уточнение содержания понятия «экономические интересы», анализ форм их проявления в действительности нуждается в дальнейшем детальном изучении.

Исследованию содержания понятия «экономические интересы», их противоречивости отводилось существенное место в исследованиях лучших представителей экономической мысли на всех этапах существования человеческого общества. В своих работах физиократы И. Бентам, Р. Оуэн, А. Сен-Симон трактовали «экономический интерес как условие оптимума экономического порядка и общественного благосостояния» [24]. Представители классической буржуазной политэкономии А. Смит, Д. Рикардо и другие обосновали приоритетность личного интереса. К. Маркс, Ф. Энгельс и их соратники исследовали взаимосвязь экономических интересов и потребностей, выявили антагонизм противоречий экономических интересов собственников условий производства и наемных работников.

Должный вклад в разработку методологии и теории экономических интересов внесли исследования представителей отечественной экономической мысли с точки зрения реализации цели данной статьи: Л. И. Абалкин [1], И. М. Авдеев [2], В. С. Загашвили [8], А. М. Румянцев [18], Н. Плискевич [17] и ряд других.

Целью настоящего исследования является уточнение содержания категории «экономический интерес», выявление взаимозависимости и взаимообусловленности экономических интересов и потребностей, анализ экономических интересов как иерархической системы, включающей три компоненты: объективность, направленность реализации экономического интереса на удовлетворение потребностей индивидов и объективно-субъективный характер проявления в реальных условиях.
Логика вариативности изучения содержания категории «экономические интересы» предполагает определенную периодизацию эволюции данного понятия.

\section{Предыстория и физиократы}

Например, К. Гельвеций отмечал, что «экономический интерес есть всесильный волшебник, который изменяет в глазах всех существ вид всякого предмета» [6, с. 67], более того, основой такого подхода является изучение категории «экономический интерес» как отношения человека и высшего разума. «Если физический мир подчинен закону движения, то мир духовный не менее подчинен закону интереса» [6, с. 124].

Относительно систематизированную модель экономических интересов создали физиократы. Они анализировали систему интересов в соответствии с классовой стратификацией общества и различали производительный, собственников и так называемый бесплодный классы. Во главу угла физиократы ставили национальные экономические интересы аграрных экономик, поступательное развитие которых обеспечивалось функционированием внутреннего рынка.

И. Бентам, Р. Оуэн, А. Сен-Симон указывали, что «экономический интерес, самому себе предоставленный, находит то, что ему более выгодно, но вместе с тем то, что наиболее выгодно для всех, соответственно свободная реализация эгоистических интересов хозяйствующими субъектами, представляется условием оптимума экономического порядка и общественного благосостояния» [24, с. 145].

\section{Классическая политэкономия и неоклассики}

Позиция А. Смита соответствовала интересам страны, зарубежная деятельность которой ориентировалась на первенство в мировом сообществе. «Адам Смит подчинил космополитизм национальным целям» [27, с. 5]. В его труде «Исследование о природе и причинах богатства народов» обоснован «естественный порядок» экономической жизни, механизм функционирования которого предусматривает взаимодействие субъектов экономики. Для каждого отдельно взятого человека главным приоритетом выступает личный интерес, но при взаимодействии с интересами других агентов происходит их гармонизация.

Одной из приоритетных идей А. Смита является мысль о том, что в основе обмена лежат интересы индивидуумов. «Человек, скорее, достигнет своей цели, если обратится к эгоиз- 
му своих ближних и сумеет показать им, что в их собственных интересах сделать для него то, что он требует от них» [21, с. 5].

Немецкий экономист, сторонник неоклассической теории Ф. Лист утверждал: «Между человеком и человечеством история поставила нации. Любой индивидуум прежде всего часть нации, и его благополучие зависит от могущества нации. У наций разные силы и разные экономические интересы, и их должны ограждать государства» [14, с. 126].

К. Маркс и его последователи, придавая особое значение классовым интересам, говорили, что «только классы, а не нации выступают субъектами мирового хозяйства» [15, с. 105]. Представители марксизма выявили взаимосвязь экономических интересов и потребностей, отразили особую роль этих отношений в жизни общества. Они показали детерминацию экономических интересов и способа производства. Логические построения марксизма базировались на изучении непримиримой противоречивости экономических интересов собственников условий производства и наемных работников.

\section{Маржинализм, утилитаризм и теория общественного благосостояния}

Стремительное развитие капиталистического рынка, возрастание роли потребителя в функционировании рыночных отношений способствовали возникновению маржинализма в ходе так называемой «маржинальной революции». В центре этой концепции находится субъект с его потребностями. Данное направление экономической мысли в самом общем плане включает три основные ветви: австрийскую, английскую и лозаннскую школы. Основополагающие моменты реформизма соответствовали национальным интересам отдельных стран.

Представители утилитаристкой концепции исключение огорчений и получение удовольствий считали основой поведения людей. Например, И. Бентам представлял интерес общества как «сумму абсолютно автономных и независимых ни от каких высших побуждений личных интересов» [9, с. 6] и рассматривал общество как «тело, составленное из индивидуальных личностей» [там же, с. 21].

Ф. Энгельс отмечал, что «экономические отношения каждого общества проявляются прежде всего через экономические интересы» [27, с. 10]. Мотивацию поведения человека определяют, во-первых, осознание им своих потребностей и, во-вторых, стремление к их удовлетворению. Суммирующей равнодейству- ющей при этом является побуждение индивида к конкретным целенаправленным действиям. Те или иные формы интересов в реальной жизни проявляются через потребности.

Взаимообусловленность интересов и потребностей корреспондируется следующим образом: с одной стороны, экономические интересы выступают формой проявления экономических потребностей, с другой - отражают динамику и уровень удовлетворения экономических потребностей, с третьей - выступают побудительным мотивом деятельности субъектов с целью удовлетворения потребностей.

В границах концепции общественного благосостояния А. Пигу «анализировал своекорыстный экономический интерес как доминирующий фактор (но не единственный), обеспечивающий максимально возможный в данных экономических условиях национальный доход и экономическое равновесие» [16, с. 35]. Иными словами, значительное влияние на экономическое благосостояния имеет корыстный интерес при том условии, что институциональные образования функционируют с целью реализации интересов.

В первой трети XX в. происходили существенные изменения в концепциях экономических интересов, которые нашли отражение в кейнсианстве. Дж. М. Кейнс, осуществляя анализ сущности экономических интересов, использовал не «микроэкономические категории, например такие, как “индивид” - “фирма”, а макроэкономические: национальный доход, потребление, сбережения, инвестиции» [11, с. 105].

Российская экономическая мысль конца XIX - начала XX в. рассматривала аспекты функционирования национальных хозяйственных проблем с позиции приоритета интересов государства Российского.

\section{Советская концепция}

Экономические интересы советскими экономистами анализировались с позиций марксистской парадигмы, как следствие, была сформирована теория экономических интересов, в которой они рассматривались «как отношения общества, класса или отдельного человека к условиям собственной жизни и наличным потребностям, которые побуждают социальный коллектив или отдельных людей содействовать сохранению условий, благоприятных для жизни и развития коллектива или личности» [18, с. 12]. С этих позиций экономический интерес и экономическая потребность представлялись как тождество. Воспроизводственный процесс и производственные связи, про- 
являющиеся через экономические отношения, способствуют реализации экономических потребностей. Например, академик А. М. Румянцев под экономическими интересами понимал «постоянно растущие потребности всех членов общества не только в средствах производства, но и в средствах существования, обеспечение полного удовлетворения которых должны быть естественным, основным стимулом непрерывного расширения и научно-технического совершенствования общественного производства в целом» $[18$, с. 236]. При такой трактовке понятие экономического интереса теряет собственное содержание как экономической категории.

Общественные интересы при социализме проявляются как интересы всего общества, способствующие удовлетворению потребностей социума. Экономический интерес отражает сущность всей совокупности экономических отношений социалистического общества. При этом общественный экономический интерес не выступает суммой интересов отдельных лиц. Государство, как представитель общества, в общем является субъектом выражения совокупного экономического интереса и представляет интересы всех слоев и классов, каждого отдельного члена и социалистического общества в целом. Коллективные и личные интересы формируются под непосредственным влиянием всеобщего интереса. Экономический интерес выступал в качестве объективного отношения людей к социалистической действительности, проявлением которого является соответствующее положение в социуме и возможность дальнейшего полноценного развития. С этих позиций экономический интерес представляется как категория экономической пользы, выгоды, которая способствует саморазвитию и самоутверждению субъекта интереса. В данном случае интерес является объективной категорией, которая способствует самоутверждению субъекта с целью реализации своих потребностей и определяется системой существующих отношений в экономике.

По мнению Л.И. Абалкина, «экономический интерес есть составляющая государственных экономических интересов, всегда и повсеместно выступал в наиболее очевидной и явной форме» [1, с. 102]. Он считал, что «стремление к предоставлению нормальных условий воспроизводства, к укреплению экономического процветания и могущества является главной пружиной во внутренней и во внешней политике государства», тем самым предопределяя его центральным носителем экономических интересов [1, с. 157].

\section{Современные концепции}

В. Загашвили отмечал, что экономический интерес государства заключается в обеспечении безопасности экономических интересов общества в целом и последние выступают как «объективные побудительные мотивы экономической деятельности, связанные со стремлением людей к удовлетворению возрастающих материальных и духовных потребностей» [8, с. 351]. В этом контексте экономические интересы проявляются в качестве двигателя экономики и базы функционирования действенного хозяйственного механизма, результатом которого может быть интенсивный путь развития экономики.

Ю. В. Яременко писал, что «экономические интересы, экономическая политика сегодня может быть только выражением экономических интересов российских производителей» $[28$, c. 256$]$. «Речь при этом идет о существовании некоторого достаточно значительного пересечения интересов, которое и может быть положено в основу единой экономической политики» [28, с. 271].

В своих работах Л. Абалкин, В. Загашвили, Ю. Яременко ставят знак равенства между понятиями «малое предпринимательство», «малый бизнес» и «предприниматель». Для них «большой бизнес» выступает как новое явление экономической действительности, функционирующее на принципиально других основах.

До сих пор ученые не пришли к какому-либо общему мнению по содержанию понятия экономического интереса. Р. Хизрич, американский профессор, трактует экономический интерес предпринимателя «как процесс создания чего-то нового, что обладает стоимостью, а предпринимателя рассматривает как человека, который затрачивает на это всё необходимое время и силы, берет на себя весь финансовый, психологический и социальный риск, получая в качестве экономического интереса деньги и удовлетворение достигнутым» [26, с. 140].

Участники рыночной системы, реализуя экономические отношения, ставят своей целью достижение определенных экономических интересов. «Экономический интерес - это реальные, обусловленные отношениями собственности и принципом экономической выгоды мотив и стимул социальных действий по удовлетворению потребностей» [4, с. 19].

Необходимость удовлетворения сформировавшихся и перспективных потребностей лич- 
ности, социальных групп и национального сообщества проявляется через реализацию экономических интересов, которые определяются экономическими отношениями как существенными и устойчивыми связями. «Будучи проявлением производственных отношений, они выступают в виде объективной направленности хозяйственной деятельности людей, в которой отражаются их место в системе общественного производства» [22, с. 15].

Французский мыслитель А. Тюрго предпринял попытку выявления связей интересов людей с их потребностями. «Относя интересы к первичной категории, а потребности - ко вторичной, он первым подошел к разделению интересов на общественные и личные» [23, с. 58].

Экономические интересы принципиально отличаются от экономических потребностей:

- во-первых, экономические интересы проявляются в действиях субъектов по реализации целей, способствующих удовлетворению потребностей;

- во-вторых, экономические интересы отражают определенную динамику и объем удовлетворения потребностей.

Многие учёные солидарны в том, что экономические интересы играют роль связующего звена между потребностями и стимулами субъектов к производственно-экономической деятельности, а также «выступают социально и исторически обусловленной необходимостью удовлетворения потребностей» [5, с. 34].

Экономические интересы влияют на всю совокупность видов деятельности человека, проявляясь как сложноподчинённая иерархическая система, выражающаяся в форме экономических потребностей.

Не без оснований многие исследователи считают, что:

- во-первых, «потребность» - более широкое понятие, вследствие того, что она является общей категорией для органической и социальной форм движения материи, выражает свойства и животного мира, и общества. Понятие «интереса» же применимо только к характеристике общественной жизни;

- во-вторых, эти понятия ориентированы на разные объекты: потребность направлена, прежде всего на предмет её удовлетворения, а интерес направлен на те социально-экономические отношения, институты, учреждения, от которых зависит распределение материальных субстанций и, которые обеспечивают удовлетворение потребностей. Интересы отражают не только потребности, как порождение природ- ного мира, но и социальную сторону условий жизни и связаны с экономическими отношениями;

- в-третьих, потребность и интерес играют функционально разные роли: потребность выступает фактором развития производства, а интерес - фактором совершенствования общества. Например, «интерес» направлен на рост эффективности, на оптимальное соотношение затрат и прибыли, а в потребности такой направленности не существует. «Интерес» играет социальную роль, делая возможным разрешение противоречия между неограниченными потребностями и ограниченными условиями их реализации» [7, с. 89].

И. Т. Корогодин определяет экономический интерес как осознанную человеком необходимость в жизненных благах, его желание, выгоду, опосредованные экономическими отношениями в виде направления хозяйственной деятельности в целях удовлетворения своих потребностей. «Экономический интерес имеет две стороны, которые находятся в противоречивом единстве. С одной стороны он субъективен, выступает побудителем внутреннего мотива поведения, с другой стороны он объективен и выражается в экономических отношениях любого общества» [12, с. 230].

И. В. Анохов различает данные категории так: «категория “экономический интерес” - это потребность на уровне общества (общественно определённые потребности), в то время как категория “потребность” может быть охарактеризована и вне этих отношений. Хотя необходимость в удовлетворении потребностей и вытекает из природы человеческого существа и значительная часть потребностей имеет физиологическую природу, тем не менее их удовлетворение происходит через процесс производства и производственные отношения и, как следствие, природа этих потребностей - социально-экономическая» [3, с. 6].

Достаточно широкое распространение получила точка зрения о взаимосвязи экономических интересов и потребностей как объективно существующей формы отношений, которые возникают в процессе деятельности отдельных субъектов. Если потребность характеризует, что нужно субъекту для его нормального функционирования, то интерес отвечает на вопрос, что необходимо сделать для удовлетворения этой потребности.

Гегель считал, что «типичными членами гражданского общества являются не такие лица, которые обладают доброй волей, направ- 
ленной на общее благо, а, скорее, те, кто свой особый экономический интерес и экономический интерес своей привилегированной корпорации делает своим ближайшим предназначением» $[25$, с. 118$]$.

Проецируя вышеизложенные положения Гегеля на современную российскую действительность, необходимо подчеркнуть, что экономические интересы Российской Федерации формируются в большей мере интересами крупных агломерационных объединений, производящих основной объем валового внутреннего продукта и поддерживающих конкурентоспособность национальной экономики, ее регионов.

Н. Плискевич пишет: «недостаточное исследование механизма использования экономических законов в значительной мере связано с недооценкой экономической наукой проблемы интересов. Наши знания о них не проникают далее обыденных представлений, нам неизвестны в полной мере ни их структура, ни их соподчиненность» [17, с. 43].

В настоящий период высвечивается проблема реализации имеющихся знаний о базе экономических интересов, их воздействии на производство в целях получения большего эффекта. Измерение и согласованность экономических интересов субъектов рыночных отношений значительно актуализировалась и приняла первостепенное значение.

Как указывает П. Игнатовский, в настоящее время в экономической науке не существует общепринятого понятия «экономического интереса, а также способов разрешения противоречий этих интересов. Несмотря на значительное количество работ, связанных с анализом различных аспектов экономических интересов, остается ряд недостаточно исследованных теоретических вопросов» [9, с. 30], например таких, как определение сущности экономического интереса. Также не в полной мере раскрыты некоторые аспекты природы возникновения экономического интереса: исторический, гносеологический и онтологический, а также факторы, которые оказывают влияние на него; условия и формы реализации интересов на определенном этапе; место и роль интересов в социально-экономической системе общества; тенденции возникновения и развития совокупности экономических интересов; закономерности её трансформации.

И. В. Анохов утверждает, что содержание интересов невозможно объяснить только наличием в обществе взаимосвязей между субъ- ектами, которые возникают в процессе воспроизводства: производства, распределения, обмена и потребления различных благ.

Сущность понятия «экономический интерес» может быть охарактеризована следующим образом: «во-первых, интересы отражают направленность субъектов на “самоутверждение”, другими словами, на сохранение или улучшение их собственного социально-экономического положения, оптимальное достижение которого возможно только на основе удовлетворения потребностей; во-вторых, непосредственная обусловленность интересов положением их носителей, в системе социально-экономических отношений такое положение принято называть социально-экономическим статусом субъектов» [3, с. 21].

Достаточно полное определение изучаемой категории представляет А. Генкин: «экономический интерес мы определяем как реальный, обусловленный отношениями собственности принцип экономической выгоды, мотив и стимул социальных действий по удовлетворению динамичных систем индивидуальных потребностей» $[10$, с. 55$]$.

Экономические интересы людей связаны с удовлетворением потребностей, которые являются отправным моментом функционирования материального производства и, кроме того, имеют большое значение для развития нематериальной сферы. Необходимость удовлетворения потребностей людей порождает экономические интересы, которые являются объективной и осознанной потребностью и движущей силой действия каждого отдельно взятого человека, коллектива и нации в целом для достижения конкретных целей. Более того, экономические интересы обусловлены системой общественного воспроизводства и положением людей в социуме. Экономические интересы выступают одной из форм проявления специфических для каждой экономической системы производственных отношений.

Существуют взаимообусловленная и сложноподчинённая взаимосвязь и взаимозависимость категории «экономические интересы», в первую очередь с такими понятиями, как экономические и социально-экономические потребности, стимулы трудовой деятельности, материальная заинтересованность и некоторыми другими. Специфику экономических интересов необходимо выявлять только на основе познания сопряженных категорий, а также их взаимовлияния. При этом необходимо также принимать во внимание то обстоя- 
тельство, что они диалектически связаны с экономическими законами, через действие которых проявляется сущность экономических интересов. При этом экономические законы в определённой степени оказывают регулирующее воздействие на формирование и реализацию экономических интересов.

Хозяйствующие субъекты в итоге выступают социальным выражением экономических интересов, более того, реальным проявлением последних является конкретный результат труда (например, товар или услуга), главное предназначение которого - удовлетворение потребностей. В качестве основной функции экономи- ческого интереса, как представляется, выступает обеспечение развития, саморазвития и самосовершенствования субъекта социума. В процессе реализации собственного интереса субъект формирует конкретную цель, определяет направления и формы её реализации, вступая при этом в экономические и другие отношения с теми или иными хозяйствующими агентами.

Анализ вышеприведенных воззрений представителей различных направлений экономической мысли на содержание понятия «экономический интерес» позволяет определённым образом их структурировать и представить в обобщенном виде (табл. 1,2 ).

Понятие «экономический интерес» в работах зарубежных авторов

Та бл иц а 1

\begin{tabular}{|c|c|c|}
\hline $\begin{array}{c}\text { Этапы развития } \\
\text { экономической } \\
\text { мысли }\end{array}$ & Авторы & Трактовка содержания понятия «экономический интерес» \\
\hline \multirow{2}{*}{ Предыстория } & К. Гельвеций & $\begin{array}{l}\text { Экономический интерес представляется всесильным волшебником, } \\
\text { который изменяет в глазах всех субъектов вид любого предмета }\end{array}$ \\
\hline & В. Гегель & $\begin{array}{l}\text { Законодательное закрепление форм и способов реализации эконо- } \\
\text { мических интересов определяет развитие государства }\end{array}$ \\
\hline \multirow{3}{*}{ Физиократы } & И. Бентам & $\begin{array}{l}\text { Экономический интерес общества является суммой личных интере- } \\
\text { сов, более того, материализация личного экономического интереса } \\
\text { выступает основополагающей целью любого государства }\end{array}$ \\
\hline & $\begin{array}{l}\text { Р. Оуэн, } \\
\text { А. Сен-Симон, } \\
\text { Ш. Фурье }\end{array}$ & $\begin{array}{l}\text { Экономический интерес является оптимальной базой экономического } \\
\text { порядка. Он самостоятельно находит то, что наиболее выгодно для всех }\end{array}$ \\
\hline & А. Тюрго & $\begin{array}{l}\text { Сущность экономического интереса проявляется в потребности, при } \\
\text { этом экономические интересы являются первичными, а потребности - } \\
\text { вторичными }\end{array}$ \\
\hline \multirow{2}{*}{ Классики } & С. Адам & $\begin{array}{l}\text { Каждый индивидуум преследует свой личный интерес, однако при стол- } \\
\text { кновении индивидуумов происходит и гармонизация их личных инте- } \\
\text { ресов. Экономический интерес, во-первых, есть побудительный мотив } \\
\text { поведения субъектов, во-вторых, в основе обмена лежат интересы людей }\end{array}$ \\
\hline & Д. Рикардо & $\begin{array}{l}\text { Проявлением экономических интересов любого общества выступа- } \\
\text { ют экономические потребности. } \\
\text { Мотивация поведения человека определяется осознанием своих по- } \\
\text { требностей и стремлением к их удовлетворению }\end{array}$ \\
\hline \multirow[b]{2}{*}{ Неоклассики } & Ф. Лист & $\begin{array}{l}\text { У каждой нации существуют национальные экономические интере- } \\
\text { сы, которые призвано защищать государство }\end{array}$ \\
\hline & А. Пигу & $\begin{array}{l}\text { Экономический интерес - это корыстный интерес, который способству- } \\
\text { ет экономическому благосостоянию при условии функционирования } \\
\text { общественных институтов, обеспечивающих реализацию интересов }\end{array}$ \\
\hline \multirow[b]{2}{*}{ Марксисты } & К. Маркс & $\begin{array}{l}\text { Экономические интересы проявляются через потребности. Им при- } \\
\text { сущ объективный характер и детерминация способом производства } \\
\text { и производственными отношениями }\end{array}$ \\
\hline & Ф. Энгельс & $\begin{array}{l}\text { Экономические интересы проявляются через экономические отно- } \\
\text { шения и в реальности принимают форму потребностей. Мотивацию } \\
\text { поведения человека формируют осознание им своих потребностей } \\
\text { и стремление к их удовлетворению }\end{array}$ \\
\hline Кейнсианство & Дж. Кейнс & $\begin{array}{l}\text { Подвергая анализу сущность экономического интереса, целесо- } \\
\text { образно использовать макроэкономические категории, такие как } \\
\text { национальный доход, потребление, сбережения, инвестиции, а не } \\
\text { оперировать микроэкономическими: индивидуум и фирма }\end{array}$ \\
\hline
\end{tabular}


Понятие «экономический интерес» в работах отечественных авторов

\begin{tabular}{|c|c|c|}
\hline $\begin{array}{c}\text { Этапы развития } \\
\text { экономической мысли }\end{array}$ & Авторы & $\begin{array}{l}\text { Трактовка содержания понятия } \\
\text { «экономические интересы» }\end{array}$ \\
\hline $\begin{array}{l}\text { Конец XIX - первая } \\
\text { четверть XX в. }\end{array}$ & $\begin{array}{l}\text { С. Витте, В. Кочинский, } \\
\text { А. Чупров }\end{array}$ & $\begin{array}{l}\text { В своих работах они отождествляли экономи- } \\
\text { ческий интерес с экономическими потребно- } \\
\text { стями }\end{array}$ \\
\hline \multirow{11}{*}{$\begin{array}{c}\text { Вторая половина XX - } \\
\text { начало XXI в. }\end{array}$} & Л. И. Абалкин & $\begin{array}{l}\text { Экономический интерес является составляю- } \\
\text { щей государственных экономических инте- } \\
\text { ресов и всегда выступает, в наиболее очевид- } \\
\text { ной и явной форме }\end{array}$ \\
\hline & И. М. Авдеев & $\begin{array}{l}\text { Экономический интерес является реалией, } \\
\text { которая проявляется через отношения соб- } \\
\text { ственности и выступает мотивом и стимулом } \\
\text { деятельности людей по удовлетворению } \\
\text { потребностей }\end{array}$ \\
\hline & И. В. Анохов & $\begin{array}{l}\text { Экономический интерес - это прежде всего } \\
\text { общественно определенные потребности, } \\
\text { но при этом последним может быть дана } \\
\text { характеристика вне экономических отно- } \\
\text { шений }\end{array}$ \\
\hline & А. Д. Бугакова & $\begin{array}{l}\text { Экономические интересы выступают посред- } \\
\text { ником между потребностями хозяйствующих } \\
\text { субъектов и стимулом к их деятельности }\end{array}$ \\
\hline & А.В. Генкин & $\begin{array}{l}\text { Экономический интерес является реальным } \\
\text { принципом экономической выгоды, а также } \\
\text { мотивом и стимулом действий по удовлетво- } \\
\text { рению индивидуальных потребностей }\end{array}$ \\
\hline & $\begin{array}{l}\text { Б. Я. Гершкович, } \\
\text { В. И. Лившиц }\end{array}$ & $\begin{array}{l}\text { Экономический интересы отражают все сфе-- } \\
\text { ры деятельности человека, формируя взаи- } \\
\text { мозависимую, сложноподчиненную систему, } \\
\text { проявлением которой выступают экономиче- } \\
\text { ские потребности }\end{array}$ \\
\hline & В. Загашвили & $\begin{array}{l}\text { Экономический интерес есть объективный } \\
\text { побудительный мотив к различным ви- } \\
\text { дам деятельности, которая направлена на } \\
\text { удовлетворение социально-экономических } \\
\text { потребностей }\end{array}$ \\
\hline & Э. А. Исраилова & $\begin{array}{l}\text { Экономический интерес выступает осознан- } \\
\text { ной потребностью индивида, коллектива } \\
\text { или общества в целом, прямо или косвенно } \\
\text { выражается в экономических благах }\end{array}$ \\
\hline & И. Т. Корогодин & $\begin{array}{l}\text { Экономический интерес есть осознанная } \\
\text { человеком необходимость в жизненных } \\
\text { благах в целях удовлетворения своих по- } \\
\text { требностей и выступает побудительным } \\
\text { мотивом к ней }\end{array}$ \\
\hline & А. М. Румянцев & $\begin{array}{l}\text { Экономические интересы - это возрастаю- } \\
\text { щие в динамике потребности общества, обе- } \\
\text { спечение удовлетворения которых возмож- } \\
\text { но только на основе научно-технического } \\
\text { развития производства }\end{array}$ \\
\hline & А. В. Тарасов & $\begin{array}{l}\text { Экономические интересы представляют } \\
\text { собой существенные и устойчивые взаимос- } \\
\text { вязи, обусловленные необходимостью удов- } \\
\text { летворения потребностей хозяйствующих } \\
\text { субъектов }\end{array}$ \\
\hline
\end{tabular}




\section{Заключение}

По нашему мнению, на основе анализа различных положений, нашедших отражения в таблице, понятие экономического интереса можно сформулировать как удовлетворение прежде всего материальных, а затем иных потребностей хозяйствующих субъектов посредством социально-экономических отношений, функционирующих в любом обществе.

Экономический интерес представляет собой сложную иерархическую систему и ему присущи следующие аспекты:

- объективность, вследствие того, что эти отношения возникают независимо от воли и сознания людей и находят своё выражение в производственных отношениях любой экономической системы;

\section{Библиографический список}

1. Абалкин Л. И. Хозяйственный механизм развитого социалистического общества. М. : Экономика, 1973.

2. Авдеев И. М. К вопросу о сущности экономического интереса // Социально-экономические явления и процессы. 2009. Вып. 1. С. 19-21.

3. Анохов И. В. О категория интереса в экономической теории // Известия ЦГЭЛ. 2010. Вып. 3. С. 5-8

4. Бентам И. Введение к принципам морали и юриспруденции. СПб. : Литера, 1998.

5. Бугакова А. Д., Тамошина Г. И. Обобществление труда и экономические интересы в развитом социалистическом обществе. Воронеж : Издательство ВГУ, 1979.

6. Гельвеций К. А. Сочинения в двух томах. М. : Мысль, 1995.

7. Гершкович Б. Я., Лившиц В. И. Экономические интересы в условиях развитого социалистического общества. М. : Высшая школа, 1995.

8. Загашвили В. С. Экономические интересы России в условиях глобализации. М. : Финстатинформ, 2010.

9. Игнатовский П. Экономические интересы и их противоречия // Экономист. 2002. №3. С. 30-34.

10. Исраилова Э. А. Эволюция взглядов на категорию «Экономический интерес» // Экономическая теория. Вестник РГЭУ. 2014. № 2. С. 52-56.

11. Кейнс Дж. М. Общая теория занятости, процента и денег. М. : Гелиос, 2002.

12. Корогодин И. Т. Личный интерес в системе элементов качества и эффективности человеческого капитала // Ученые записки. 2003. Вып. 1. C. 230-234.

13. Купряжкин Д. А. Основные причины и факторы ускорения виртуализации экономики современного социума // Вестник Воронежского госу-
- реализация экономического интереса направлена на удовлетворение социально-экономических потребностей людей, которое обусловлено использованием жизненных благ, созданных в процессе производства;

- проявление экономического интереса в реальной действительности имеет объективно-субъективный характер проявления вследствие того, что он по своей гносеологии объективен, но реализуется через субъективную деятельность людей.

Подводя некоторый итог, необходимо подчеркнуть, что проблема определения сущности и содержания экономического интереса продолжает оставаться дискуссионной и требует дальнейшей проработки.

дарственного университета. Серия : Экономика и управление. 2018. №. 1. С. 15-18.

14. Лист Ф. Национальная система политической экономии. - СПб. : Литера, 1999.

15. Маркс К., Энгельс Ф. Из ранних произведений. М. : Госполитиздат, 1956.

16. Пигу А. Экономическая теория благосостояния. М. : Мысль, 1985.

17. Плискевич Н. Система «власть - собственность» в современной России // Вопросы экономики. 2008. № 5. С. 43-47.

18. Румянцев А. М. Политическая экономия : в 4 т. М. : Прогресс, 1990. Т. 1.

19. Селден Р. Современная экономическая мысль. М. : Прогресс, 1981.

20. Сироткина Н. В. Индикативное управление социльно-экономическими системами // Вестник Воронежского государственного университета. Серия: экономика и управление. 2017. № 4. С. 96-106.

21. Смит А. Исследование о природе и причинах богатства народов. М. : Ось-89, 1997.

22. Тарасов А. В. Экономические интересы субъектов: противоречия и способы их разрешения : монография. Воронеж : Издательство ВГУ, 2009.

23. Тюрго А. Р. Избранные экономические произведения. М. : Эксмо, 1991.

24. Фролова Т. А. История экономических учений : конспект лекций. Таганрог : ТРТУ, 2004.

25. Хандруев А. А. Гегель и политическая экономия. М. : Экономика, 1990.

26. Хизрич Р., Майкл П. Предпринимательство или как завести собственное дело и добиться успеха. М. : Прогресс-Универс, 1991.

27. Энгельс Ф. Происхождение семьи, частной собственности и государства. М. : Политиздат, 1986.

28. Яременко Ю. В. Теория и методология исследования многоуровневой экономики. М. : Наука, 2000. 
Миронова Ирина Станиславовна, кандидат экономических наук, доцент кафедры экономической безопасности и бухгалтерского учета, Воронежский государственный университет, Воронеж, Российская Федерация

E-mail: irina.mironova.13.05.1975@mail.ru ORCID ID: 0000-0002-9230-1155
Сотников Станислав Михайлович, кандидат экономических наук, доцент кафедры экономики, маркетинга и коммерции, Воронежский государственный университет, Воронеж, Российская Федерация

E-mail: ectr@econ.vsu.ru

ORCID ID: 0000-0002-2773-0092

Поступила в редакцию 15.02.2021

Подписана в печать 14.03.2021 


\title{
Epistemology of the development of the category «Economic interests»
}

\author{
I. S. Mironova ${ }^{1 \bowtie}$ S. M. Sotnikov ${ }^{2}$ \\ ${ }^{1,2}$ Voronezh State University, 1 University sq., 394018, Voronezh, Russian Federation
}

Cite as: Mironova, I. S., Sotnikov, S. M. (2021) Epistemology of the development of the category «Economic interests». Proceedings of Voronezh State University. Series: Economics and Management. 1, 25-36. (In Russ., abstract in Eng.). DOI: 10.17308/econ.2021.1/3347

Importance. Economic relations between agents of the market system regarding the emergence and existence of economic interests, as well as the analysis of theoretical and methodological problems of the essence and content of the category of «economic interests» as the most important motive and stimulus for the activities of subjects in the concepts of foreign and domestic researchers of this problem.

Purpose. An attempt has been made to clarify the content of the economic category «economic interests»; to reveal the interdependence and interdependence of economic interests and needs; determine which of them is primary and which is secondary; explore this concept as a complex hierarchically subordinate system.

Methodology. In the process of studying the problems of the emergence and development of economic interests of economic entities, the methods of system-functional analysis, scientific abstraction, general and special, analysis and synthesis, ascent from the concrete to the abstract and vice versa, the unity of historical and logical approaches were used.

Results. The analysis of the main provisions reflecting the content of the considered category is carried out, its relationship with consumption is revealed, the specificity of these relations is reflected, the forms of manifestation of interests in reality are indicated. The authors have given the content of the category of «economic interest», which is a hierarchical system that includes the following aspects: first objectivity, since these relationships arise independently of the will and consciousness of people; the second - the realization of economic interest contributes to the satisfaction of the needs of individuals; the third is the objective-subjective nature of manifestation in real conditions, because economic interest is objective in nature, but is realized through the subjective activity of people.

Conclusions. The content of the category «economic interest» has been clarified as the need to satisfy, first of all, the material needs of economic entities through socio-economic relations. Economic interest is a multi-level complex hierarchical system, which is characterized by objectivity, focus on meeting the needs of individuals, an objective-subjective form of manifestation in reality.

Key words: economic interests, controversies, models, economic entities, satisfaction of needs, industrial relations, economic relations, economic benefit, motives of activity, property relations, economic category, objectivity, society reproduction, incentives of labour activities.

\section{Conflict of Interest}

The authors declare the absence of obvious and potential conflicts of interest related to the publication of this article.

\section{References}

1. Abalkin, L.I. (1973) Hozyaistvennyi mekhanizm razvitogo socialisticheskogo obshchestva [The economic mechanism of a developed socialist society]. Moscow, Economics publ. (In Russian)

2. Anokhov, I.V. (2010) About interest category in economic theory. Bulletin of Baikal State University. 3, 5-8. (In Russian)
3. Avdeev, I.M. (2009) About the essence of economic interest. Social-Economic Phenomena and Processes. 1, 19-21. (In Russian)

4. Bentham, J. (1998) An introduction to the principles of morals and legislation. Saint-Petersburg, Litera Publ. (In Russian)

5. Bugakova, A. \& Tamoshina, G. (1979) Obobshchestvlenie truda i ekonomicheskie interesy $v$ razvitom 
socialisticheskom obshchestve [Socialization of labor and economic interests in a developed socialist society]. Voronezh, VSU Publ. (In Russian)

6. Helvetsi, A. (1995) Sochineniya v dvuh tomah [Essays in two volumes]. Moscow, Mysl' Publ. (In Russian)

7. Gershkovich, B. \& Livshits, V. (1995) Ekonomicheskie interesy $v$ usloviyah razvitogo socialisticheskogo obshchestva [Economic interests in the context of the development of a socialist society]. Moscow, HSE University Publ. (In Russian)

8. Zagashvili, V. (2010) Ekonomicheskie interesy Rossii v usloviyah globalizacii [Russia's economic interests in the context of globalization]. Moscow, Finstatinform Publ. (In Russian)

9. Ignatovsky, P. (2002) Ekonomicheskie interesy $\mathrm{i}$ ih protivorechiya [Economic interests and their counteraction]. Ekonomist. 3, 30-34. (In Russian)

10. Israilova, E.A. (2014) Evolyuciya vzglyadov na kategoriyu «Ekonomicheskij interes» [Evolution of views on the category of " Economic interest"]. Vestnik RSUE. 2, 52-56. (In Russian)

11. Keynes, J. (1936) The General Theory of Employment, Interest and Money. Palgrave Macmillan.

12. Korogodin, I. (2003) Lichnyj interes v sisteme elementov kachestva i effektivnosti chelovecheskogo kapitala [Personal interest in the system of elements of quality and efficiency of human capital]. Uchenye zapiski. 1, 230-234. (In Russian)

13. Kupryazhkin, D.A. (2018) The main causes and factors accelerating the economy's virtualization in modern society. Proceedings of Voronezh St. Univ. series: economics and management. 1, 15-18. (In Russian)

14. List, F. (1841) Das nationale System der politischen Ökonomie. Stuttgart/Tübingen. (In German)

15. Marx, K. \& Engels, F. (1956) Iz rannih proizvedenij [From early works]. Moscow, Gospolitizdat publ. (In Russian)

16. Pigou, A. (1920) The Economics of Welfare. London, Macmillan.
17. Pliskevich, N. (2008) Sistema «vlast' - sobstvennost'» v sovremennoj Rossii [The system of «power - property» in modern Russia]. Voprosy ekonomiki. 5, 43-47. (In Russian)

18. Rumyancev, A. (1990) Politicheskaya ekonomiya [Political economy]. Moscow, Progress Publ., Vol. 1. (In Russian)

19. Selden, R. (1981) Sovremennaya ekonomicheskaya mysl' [Modern economic ideas]. Moscow, Progress Publ. (In Russian)

20. Sirotkina, N. (2017) Indicative management of social-economic systems. Proceedings of Voronezh St. Univ. series: economics and management. 4, 96-106. (In Russian)

21. Smith, A. (1776) An Inquiry into the Nature and Causes of the Wealth of Nations. London, W. Strahan and T. Cadell.

22. Tarasov, A. (2009) Ekonomicheskie interesy sub"ektov: protivorechiya i sposoby ih razresheniya [Economic interests of subjects: contradictions and ways of their resolution]. Voronezh, Voronezh St. Univ. Publ. (In Russian)

23. Turgot, A. (1991) Izbrannye ekonomicheskie proizvedeniya [Selected economic works]. Moscow, Eksmo Publ. (In Russian)

24. Frolova, T. (2004) Istoriya ekonomicheskih uchenij [History of economic studies]. Taganrog, TRTU Publ. (In Russian)

25. Handruev, A. (1990) Gegel' i politicheskaya ekonomiya [Gegel and politicial economy]. Moscow, Economika Publ. (In Russian)

26. Hisrich, R. \& Michael, P. (1991) Entrepreneurship: Starting, Developing, and Managing a New Enterprise. London, Richard D Irwin Publ.

27. Engels, F. Der Ursprung der Familie, des Privateigentums und des Staats. 1884 (In German)

28. Yaremenko, Y. (2000) Teoriya i metodologiya issledovaniya mnogourovnevoj ekonomiki [Theory and methodology of multilevel economy research]. Moscow, Nauka Publ. (In Russian)
Irina S. Mironova, Cand. Sci. (Econ.), Assoc. Prof., Department of Economic Security and Accounting, Voronezh State University, Voronezh, Russian Federation

E-mail: irina.mironova.13.05.1975@mail.ru ORCID ID: 0000-0002-9230-1155
Stanislav M. Sotnikov, Cand. Sci. (Econ.), Assoc. Prof., Department Department of Economics, Marketing and Commerce, Voronezh State University, Voronezh Russian Federation

E-mail: ectr@econ.ru

ORCID ID: 0000-0002-2773-0092

Received 15.02.2021

Accepted 14.03.2021 